\title{
Unidirectional infiltration method to produce crown for dental prosthesis application
}

\author{
F. H. D. Pontes ${ }^{1}$; S. P. Taguchi ${ }^{1,2}$; L. A. Borges Jr. ${ }^{2}$;. P. B. Machado ${ }^{3}$; C. Santos ${ }^{1,4}$ \\ ${ }^{1}$ Universidade de São Paulo- Escola de Engenharia de Lorena, USP-EEL/DEMAR. Pólo \\ Urbo-Industrial, Gleba Al-6, s/n, Lorena-SP, CEP. 12600-000, Brasil \\ ${ }^{2}$ Centro Universitário de Volta Redonda, Av. Paulo Erlei Alves Abrantes, 1325, Volta \\ Redonda - RJ, CEP: 27240-560, Brasil \\ ${ }^{3}$ Instituto Nacional de Pesquisas Espaciais, INPE/LAS, Av. dos Astronautas, 1758, São \\ José dos Campos - SP, CEP. 12227-010, Brasil \\ ${ }^{4}$ ProtMat Materiais Avançados - Rua José Moreti, 30, módulo 18, Beira Rio II, \\ Guaratinguetá-SP,CEP 12517-660, Brasil
}

Key-words: bioceramics, dental prosthesis, alumina, infiltration, REglass.

\begin{abstract}
Alumina ceramics have been used in dental prosthesis because it is inert, presents higher corrosion and shear resistance when compared to metals, excellent aesthetic, and mechanical resistance. In this work it was produced an infrastructure material for applications in dental crowns, obtained by glass infiltration in alumina preforms. Various oxides, among that, rare-earth oxide produced by Xenotime, were melted at $1450^{\circ} \mathrm{C}$ and heat treatment at $700^{\circ} \mathrm{C}$ to obtain the glass (REglass). The alumina was pre-sintered at $1100^{\circ} \mathrm{C}$ cut and machined to predetermine format (unidirectional indirect infiltration) and finally conducted to infiltration test. The alumina was characterized by porosity ( $\mathrm{Hg}$-porosity and density) and microstructure (SEM). The glass wettability in alumina was determined as function of temperature, and the contact angle presented a low value $\left(\theta<90^{\circ}\right)$, showing that glass can be infiltrated spontaneously in alumina. The infiltration test was conducted at glass melting temperature, during 30,60, 180, 360 minutes. After infiltration, the samples were cut in longitudinal section, ground and polished, and analyzed by XRD (crystalline phases), SEM (microstructure) and EDS (composition). The REglass presents higher infiltration height when compared to current processes (direct infiltration), and homogeneous microstructure, showing that it is a promising method used by prosthetics and dentists.
\end{abstract}

\section{Introduction}

Currently the most bio-inert ceramics used as biomaterials are alumina and zirconia-based ceramics, because they are quite stable with little likelihood of adverse biological response. They are usually employed as material infrastructure, suitable for crowns or abutments. An example of conventional processing of ceramics combines the processes of sintering and infiltration of a glass (slip casting). In this case distilled water is mixed, drop by drop, with powdered glass to take a sandy consistency. Using a brush the surface of the ceramic substrate is coated and infiltration occurs near $1080^{\circ} \mathrm{C}$ in a time of 1 to 2 hours and may reach 6 hours depending on the furnace and the desired height of infiltration, see Fig. 1.

The infiltration can be promoted by direct or indirect method. Pan et al.[1] found that the indirect method of infiltration, the liquid is consumed at a lower rate allowing the expulsion of gases inside the pores, producing a microstructure more suitable for structural applications. This process has grown to become one of the most significant methods of composite production, mainly ceramic-metal composites. The spontaneous process of infiltration is very attractive because in this process external pressure is not used, and it is more economical than the process in which external pressure is used. [2-11]. 


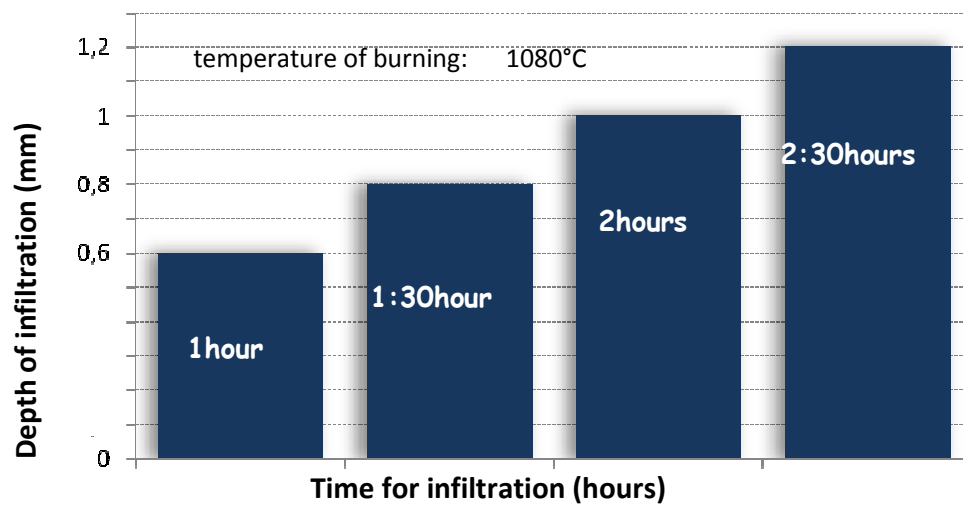

Fig.1 - Depth versus time of conventional infiltration of AllGlass ${ }^{\circledR}$ in alumina ceramics.

The capillarity is the driving force of the spontaneous liquid infiltration into packed particulate preforms, and depends strongly on the shape and size of the interconnected pores, and liquid-solid wettability of the performs [12]. Theoretical treatments are based on the assumption that pores are a bundle of parallel capillaries forming a complex pore structure in the preforms. It makes very difficult to apply simple capillarity rise and viscous flow equations to infiltration, but some experimental results illustrated that the infiltration kinetics depends on the viscosity and density of the liquid $[8,10,11]$. Usually the kinetics infiltration curve (infiltration height versus time) presents exponential behavior [13-16].

A detailed study of direct and indirect infiltration will evaluate the performance of a glass in dental ceramic infrastructure aiming future structural comparisons with commercial products.

\section{Experimental Procedures}

The glass composition is shown in Table 1, and the $\mathrm{RE}_{2} \mathrm{O}_{3}$ composition is shown in Table 2 .

Table 1 - Composition of the RE-glass

\begin{tabular}{cc}
\hline Oxide & Composition (wt.\%) \\
\hline $\mathrm{Al}_{2} \mathrm{O}_{3}$ & 18 \\
$\mathrm{SiO}_{2}$ & 18 \\
$\mathrm{~B}_{2} \mathrm{O}_{3}$ & 8 \\
$\mathrm{TiO}_{2}$ & 5 \\
$\mathrm{RE}_{2} \mathrm{O}_{3}$ & 47 \\
$\mathrm{CaO}$ & 4 \\
\hline $\mathrm{RE}=$ mixed of yttrium and rare-earth oxides.
\end{tabular}

Table 2 - Chemical composition of $\mathrm{RE}_{2} \mathrm{O}_{3}$.

\begin{tabular}{cccc}
\hline Oxides & $\begin{array}{c}\text { Composition } \\
\text { (wt.\%) }\end{array}$ & Oxides & $\begin{array}{c}\text { Composition } \\
\text { (wt.\%) }\end{array}$ \\
\hline $\mathrm{Y}_{2} \mathrm{O}_{3}$ & 44.1 & $\mathrm{Sm}_{2} \mathrm{O}_{3}$ & 0.45 \\
$\mathrm{Yb}_{2} \mathrm{O}_{3}$ & 19.2 & $\mathrm{ZrO}_{2}$ & 0.16 \\
$\mathrm{Er}_{2} \mathrm{O}_{3}$ & 13.6 & $\mathrm{Nd}_{2} \mathrm{O}_{3}$ & 0.15 \\
$\mathrm{Dy}_{2} \mathrm{O}_{3}$ & 10.5 & $\mathrm{CeO}_{2}$ & 0.09 \\
$\mathrm{Ho}_{2} \mathrm{O}_{3}$ & 3.16 & $\mathrm{CaO}$ & 0.06 \\
$\mathrm{Tm}_{2} \mathrm{O}_{3}$ & 2.88 & $\mathrm{La}_{2} \mathrm{O}_{3}$ & 0.04 \\
$\mathrm{Lu}_{2} \mathrm{O}_{3}$ & 2.55 & $\mathrm{Eu}_{2} \mathrm{O}_{3}$ & 0.02 \\
$\mathrm{Gd}_{2} \mathrm{O}_{3}$ & 1.26 & $\mathrm{TiO}_{2}$ & 0.01 \\
$\mathrm{~Tb}_{4} \mathrm{O}_{7}$ & 0.88 & & \\
\hline
\end{tabular}


The oxides was mixed in attrition mill for 1 hour in isopropyl alcohol environment, and dried in furnace IT-No 08/LCE, at $100^{\circ} \mathrm{C}$. This mixture was melted at $1450^{\circ} \mathrm{C}$ put into molds shaped bar, Fig. 2(a), annealed at $700^{\circ} \mathrm{C}$ for 30 minutes, and cooled slowly to preventing of residual stress response by degradation.
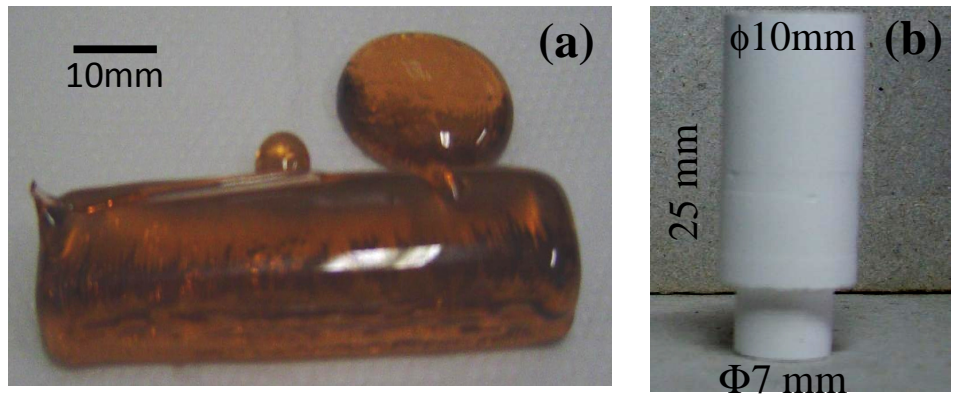

Fig.2 - Shape of (a) glass and (b) alumina substrate pre-sintered.

The alumina powder (ProtMat Materiais Avançados LTDA) were cold uniaxial pressed at $80 \mathrm{MPa}-60 \mathrm{sec}$, and pre-sintered in air at temperatures of 1000 and $1100^{\circ} \mathrm{C}$ for 30 minutes in $\mathrm{MoSi}_{2}$ furnace to acquire sufficient strength for machining. One part of substrate was cut in a plaque shape to direct infiltration, and other was machining as Fig.2 (b) to indirect infiltration method.

A preliminary wetting test was done according DIN 51730 norm, aiming to determine the melting temperature of the glass. The glass with $\phi 3 \mathrm{~mm} \times 3 \mathrm{~mm}$ was put on dense (TD>99\%) alumina substrate, and the set was heated until $1400^{\circ} \mathrm{C}$. The contact angle was measure in a function of temperature using CCD camera/image analyzing computer.

The alumina substrate $(\mathrm{TD}=75 \%)$, Fig. 2(b), was put on glass, and the unidirectional infiltration test was performed into dense alumina crucible, during 30, 120 and 240 minutes of isotherms, at heating rate of $20^{\circ} \mathrm{C} / \mathrm{min}$. The scheme of indirect method of infiltration is shown in Fig. 3.

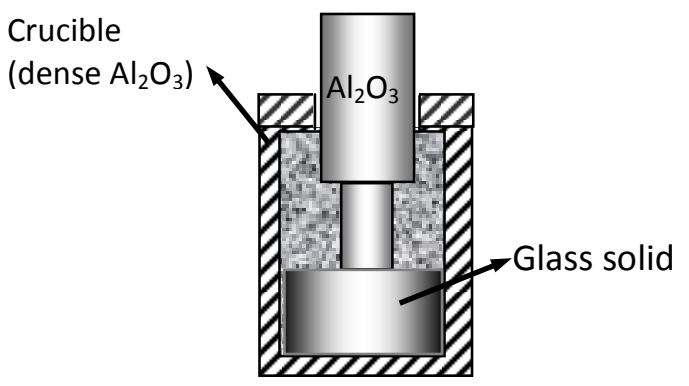

(a)

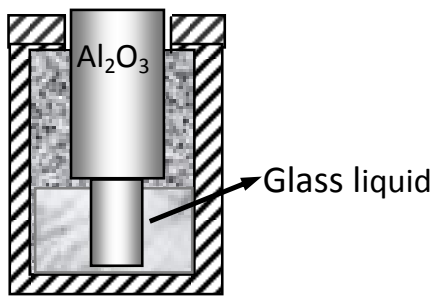

(b)

Fig. 3 - Schemes of $\mathrm{Al}_{2} \mathrm{O}_{3}$ /glass/crucible used in the infiltration tests: (a) before glass melting, and (b) after glass melting.

The direct infiltration (conventional method) was done using the same conditions than the unidirectional infiltration, but the glass-powder was put directly on the alumina substrate plaque.

After infiltration test (direct and indirect), the samples were cut across longitudinal section, ground and polished. The infiltration height and microstructure of the samples were analyzed and compared.

\section{Results and Discussion}

The melting temperature of glass was $1390^{\circ} \mathrm{C}$, according the middle sphere formed during the wetting test. The final contact angle was $12^{0}$, Fig. 4(b), showing a good wetability of glass on 
alumina surface. The glass present soft spreading and good adherence on alumina substrate. This adherence probably is because the glass interaction with alumina, as shown in white layer formed in interface, Fig. 4 (c).
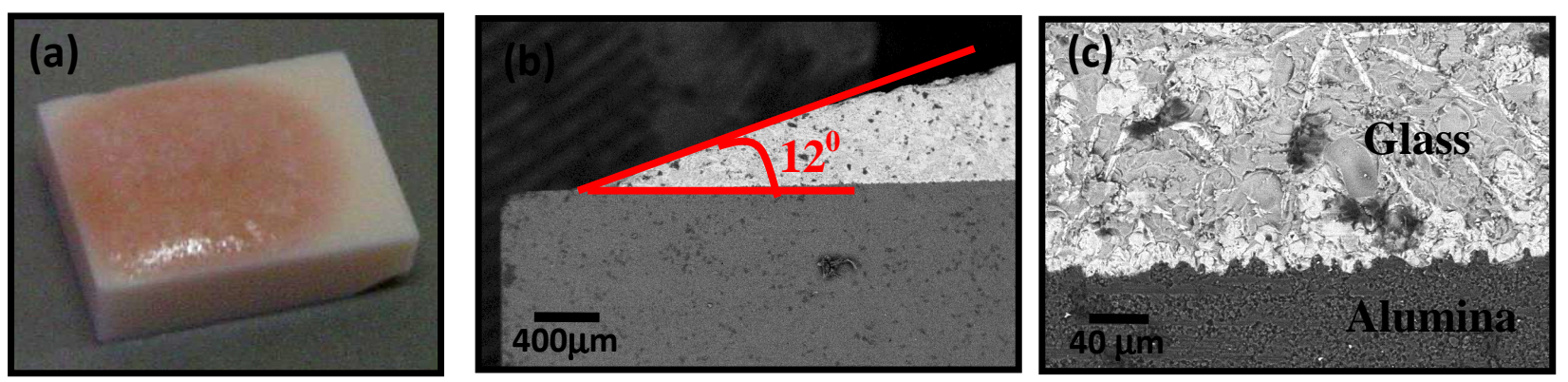

Fig. 4 - Wettability test of glass on alumina substrate: (a) after test; (b) contact angle measured at cross section; (c) microstructure (SEM) of alumina/REglass interface.

The indirect infiltration of glass in alumina substrate pre-sintered at $1100^{\circ} \mathrm{C}$ is shown in Fig. 5 , and the profile of infiltration change with time. In just 30 minutes, Fig 5(a), the profile of infiltration is ascendant, but the infiltrated region not exceeded the region's discarded, so the height of infiltration can not be considered. For 120 minutes the infiltration, Fig. 5(b), reaches $2.5 \mathrm{~mm}$ with homogeneous pattern, and 240 minutes, Fig. 5(c), the height of infiltration is $4.2 \mathrm{~mm}$ with downward trend of infiltration. This behavior means that the equilibrium of the system was reached in about 240 minutes of infiltration. From this time the glass interacts with the alumina and modifying the mechanism of infiltration. Up to 120 minutes of infiltration, the liquid rise on the substrate by the capillary principle. When the height was $4.2 \mathrm{~mm}$ ( 240 minutes), the behavior of infiltration changes and the liquid reached the hydrostatic equilibrium, and more time than this the effect of gravity causing the liquid downward trend.

The microstructure of non-infiltrated region of sample exposure during 30 minutes has porous morphology, whereas for 240 minutes of exposure the alumina substrate started to sinter. The microstructure of the infiltrated region of the sample exposed for 30 minutes has small grains of alumina (dark gray), glass (light gray) and some remaining porosity of the substrate. This porosity does not seem to decrease with increasing time of infiltration, but only the coalescing phases of alumina and glass, leading to enlargement of the grains.

The indirect method of infiltration is important to set the time and height of the infiltration system (glass/alumina). The equilibrium conditions are useful to define the actual circumstances in which this system should be used in the practice.

Fig. 5(d) shows an example of the sample infiltrated during 240 minutes. The infiltrated region present pinkish-yellow color, very interesting for implants applications. For apparent application the ceramic needs to be covered for example with porcelain.

The behavior of infiltration is the same to alumina pre-sintered at 1000 and $1100^{\circ} \mathrm{C}$, differing only in height of infiltration, because of this, only the second is shown in Fig. 5.

The height of infiltrations, for all samples is shown in Fig. 6. The substrate with bigger height value is alumina pre-sintered at $1100^{\circ} \mathrm{C}$, because presents small porous size than sample presintered at $1000^{\circ} \mathrm{C}$. When the porous size is small the capillary force grows as well as the height of infiltration.

Theoretically, the direct method of infiltration should be more efficient than the indirect method, because the capillarity and gravity infiltration developed in the same direction, while the indirect method capillarity and gravity are in opposite directions. But this behavior not occurs. In the direct method of infiltration the output of gas trapped into pores races with fill glass. Since the indirect method tends to eliminate the gas by filling glass, reaching maximum height of infiltration and more homogeneous microstructure. 


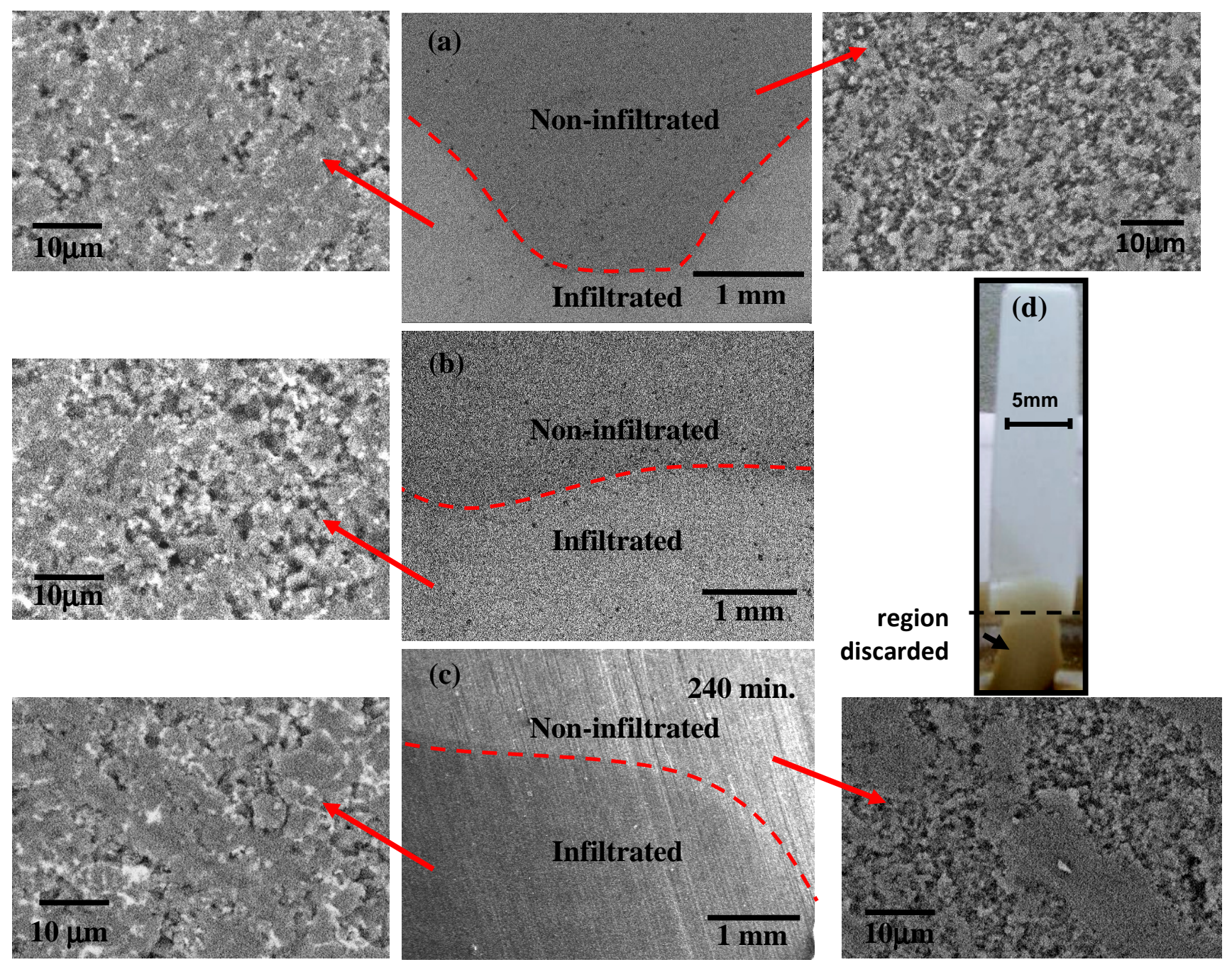

Fig. 5 - Image obtained by SEM of the indirect method of infiltration of REglas into alumina pre-sintered at $1100^{\circ} \mathrm{C}$ during (a) 30 minutes; (b) 120 minutes; (c) 240 minutes with their respective microstructure of the infiltrated region (left) and non-infiltrated region (right); (d) photo of the sample infiltrated for 240 minutes.

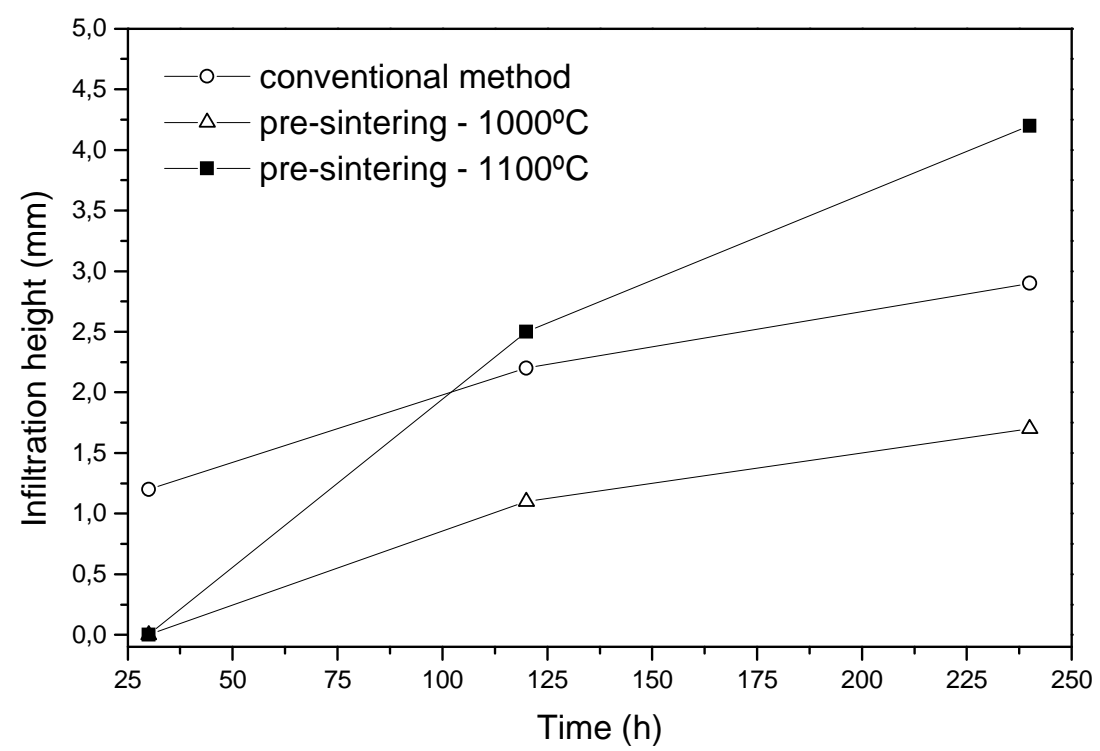

Fig 6 - Infiltration height in a function of time, using direct and indirect method (presintering at 1000 and $1100^{\circ} \mathrm{C}$ ). 


\section{Conclusions}

The indirect method of infiltration is essential to determine the equilibrium of a system, ie, the time and height of maximum infiltration that can be achieved for system. For alumina presintered at $1000^{\circ} \mathrm{C}$, the equilibrium was reached in 120 minutes, after this time the height of infiltration not changes significantly. For alumina pre-sintered at $1100^{\circ} \mathrm{C}$, the equilibrium was reached at 240 minutes with $4.2 \mathrm{~mm}$ height. The direct method (conventional) presents similar behavior of infiltration that indirect method of infiltration to alumina pre-sintered at $1000^{\circ} \mathrm{C}$, and first present better values of height. All conditions presented in this work attends the height to applications such as infrastructure ceramic for dental prosthesis, usually limited in $1 \mathrm{~mm}$ for aesthetic reasons, but the indirect method of infiltration to alumina pre-sintered at $1100^{\circ} \mathrm{C}$ present the best results.

The REglass is cheaper than the commercial glasses; it replaces the lanthanum oxide by mixed oxide of yttrium and rare earths. But REglass has a melting point of $100^{\circ} \mathrm{C}$ above the commercial glasses, and presents pinkish-yellow color. The composition of the REglass should be little changed to become commercially competitive.

The direct infiltration method introduces less glass into alumina ceramic than the indirect method, and only for 240 minutes this system attend the thickness normally used by prosthetic.

\section{Acknowledgment}

Claudinei dos Santos thanks CNPq for financial support (Jovem Pesquisador em Nanotecnologia)

\section{References}

[1] Y. Pan, M.X. Gao, F.J. Oliveira, J.M. Vieira, J.L. Baptista,: Materials Science \& Engineering. A 359 (2003) 343-349.

[2] M.R. Reyes, M.I.P. Canul, E.E.P. Medécigo, A. Gorokhovsky,: Materials Letters 57 (2003) 2081-2089.

[3] K. Konopla, A. Olszówka-Myalska, M. Szafran: Materials Chemistry and Physics 81 (2003) 329-332.

[4] N. Frange, N. Levin, M. Gelbstein, M.P. Dariel: Journal of Materials Processing Technology 486-490 (2003) 143-144.

[5] M.X. Gao, Y. Pan, F.J. Oliveira, J.L. Baptista, J.M. Vieira: Materials Letters 58 (2004) 17611765.

[6] N.A. Travitztky, E.Y. Gutmanas, N. Claussen: Materials Letters 33 (1997) 47-50.

[7] V.M. Kevorkijan: Composites Science Technology 59, (1999) 683-686.

[8] X.J. Sheng, H. Xu, Z.H. Jin, Y.L. Wang: Materials Letters 58 (2004) 1750-1753.

[9] A. Mattern, B. Huchler, D. Staudenecker, R. Oberacker, A. Nagel, M. J. Hoffmann: Journal of the European Ceramic Society 24, (2004) 3399-3708.

[10]W.C. Tu, F.F. Lange: Journal of the American Ceramic Society 78 (12) (1995) 3277-3282.

[11]Y. Pan, J.L. Baptista: Journal of the European Ceramic Society 18 (1998) 201-207.

[12]S.P. Taguchi, S. Ribeiro, R.M. Balestra:Ceramics International 34 (2008) 625-629.

[13]B.V. Zhmud, F. Tiberg, K. Hallstensson: Jounal of Colloid and Interface Science 228 (2000) 263-269.

[14]H. Caps, S.J. Cox, H. Decauwer, D. Weaire, N. Vancerwalle: Colloids and Surfaces A: Physicochemical and Engineering Aspects 261 (2005) 131-134.

[15]A. Siebold, M. Nardin, J. Schultz, A. Walliser, M. Oppliger: Colloids and Surface A: Physicochemical and Engineering Aspects 161 (2000) 81-87.

[16]S.P. Taguchi, R.M. Balestra, G.C.R. Garcia, S. Ribeiro: Ceramic International, In Press, 2009. 